УдК 330

\title{
ОТДЕЛЬНЫЕ СОЦИАЛЬНЫЕ ПРОБЛЕМЫ ПРИ ЦИФРОВОЙ ЭКОНОМИКЕ
}

\author{
Фаркова Наталья Анатольевна \\ канд. физ.-мат. наук, доцент \\ Дипломатическая академия МИД России
}

\begin{abstract}
Аннотация: При быстром развитии цифровой экономики жизненные ориентации и ценности, социальные роли и статус человека, а также его деятельность и поведение претерпевают значительные изменения. Поэтому актуальны вопросы адаптации людей к новой реальности, формирования нового мировоззрения в условиях развития технологий. Рассматривается влияние цифровых технологий на изменение ценностей и подходов к жизни современного человека.
\end{abstract}

Ключевые слова: цифровая экономика, цифровое общество, виртуальное пространство, технологии.

\section{SEPARATE SOCIAL PROBLEMS IN THE DIGITAL ECONOMY}

\section{Farkova Natalia Anatolievna}

Abstract: With the rapid development of the digital economy, life orientations and values, the social role and status of a person, as well as his activities and behavior, are undergoing significant changes. Therefore, the issues of adaptation of people to a new reality, the formation of a new worldview in the context of technology development are relevant. The influence of digital technologies on changing values and approaches to the life of a modern person is considered.

Key words: digital economy, digital society, virtual space, technology.

Одна из ключевых проблем, требующих своего решения при переходе к постиндустриальному обществу, состоит в создании эффективного дружелюбного технологического пространства как среды обитания человека.

Цифровая экономика стала движущей силой экономического роста, способной привести к значительным экономическим сдвигам, оказать влияние 
на целые области бизнеса, рынок труда и образ жизни людей. Несмотря на ставший уже привычный оборот «цифровая экономика», в научной среде нет общепринятого определения понятия «цифровая экономика» и понятий многих явлений, в том числе и социальных, которые в условиях цифровой экономики приобрели новое значение.

На сегодня в среде цифровой экономики удалось разрешить множество проблем, относящихся к сфере торговли, решать вопросы трудоустройства, оплаты различных услуг, также решать проблемы в сфере образования и здравоохранения, что особенно важным оказалось в период пандемии. Цифровая экономика, по сути, предоставила возможности новых видов современного обучения, развития инновационных медицинских технологий. Появилась возможность заработки и оказания различных информационных услуг из дома. Возможности виртуальных путешествий так же являются следствием цифровой экономики. В сфере бизнеса цифровая экономика предоставила надёжную информационную платформу, что приводит к интенсификации и повышению производительности предпринимательской деятельности на фоне уменьшения затрат.

Мы являемся свидетелями того, как интенсивное развитие получают работы по созданию искусственного интеллекта, био- и медицинских технологий. Именно эти сферы являются ключевыми в обеспечении жизнедеятельности человека. Таким образом, технологический каркас будущего составят энергетика, информация, биология, медицина, искусственный интеллект. При рассмотрении вопросов формирования технологического пространства как среды обитания человека, особого внимания требуют решение задачи обеспечения безопасности - экологии технологий. Как показывает практика, бесконтрольное использование современных технологий может привести к значительным негативным последствиям.

Использование современных технологий требует соответствующего уровня культуры. При ее недостатке высока вероятность крупных техногенных катастроф.

Малая занятость населения в активной созидательной жизни влечет большие риски не только в психологическом плане, но может привести и к нестабильности в целом в обществе и государствах. Социальные опросы. в различных странах свидетельствует о том, что общество не готово к тому, что его большая часть будет безработными даже при наличии достаточных средств на их содержание. 
Исследователи НИУ ВШЭ отмечают: «Цифровизация обеспечивает фундаментальные преобразования во всех сферах жизни и деятельности человека. Технологии становятся далеко не только двигателем развития новых отраслей, но и обретают важные социальные роли, внося значимый вклад в решение проблем общества, таких как старение населения, социальное расслоение, экологические проблемы и изменение климата. С помощью передовой науки и технологий возникает «умное» общество, базирующееся на новых ценностях ориентации на потребности человека, гибкости, креативности. Под влиянием цифровизации кардинально меняются рынок труда, здравоохранение, образование, пространственное развитие» $[1$, с. 17$]$

Согласно ежегодному отчёту о состоянии цифровой сферы Global Digital 2021 мобильными телефонами пользуется 66,6\% мирового населения. На январь 2021 года интернетом пользовалось 4,66 миллиарда человек, что на 316 миллионов больше, чем в прошлом году. В мире 4,2 миллиарда пользователей социальных сетей, рост составил более 13\% за год. В 2021 году социальными сетями пользуются 53,6\% мирового населения.

Более половины из используемых сегодня мобильных устройств относятся к классу «умных», поэтому людям становится все проще получить доступ ко всем возможностям, которые предлагает интернет, где бы они ни находились. Эти данные наглядно показывают, что компьютеры и мобильные устройства в современном обществе для большинства населения выполняют функцию «убийц свободного времени».

Еще в 2015 году экспертами Давосского форума были выделены 21 пункт переломных моментов, которые ожидаются до 2025 . Сформулированные рекомендации представляются для корпораций, стран и политических деятелей непосредственными указаниями, как следует действовать, чтобы остаться в общем тренде. При воплощении хотя бы части этих пунктов человек лишается личного пространства. Даже выключенный мобильный телефон позволяет определить местоположение владельца, телевизоры ряда фирм «шпионят» за своими хозяевами, а интернет-браузер «подбрасывает» пользователям ориентированную на них рекламу и статьи, несомненно влияющие на адресатов, а также «помнит» все их запросы. Вживляемые мобильные телефоны, интернет-очки, одежда, подключенная к интернету, тотальная «смартфонизация» интернет вещей сделают мир «прозрачным», а каждого человека постоянно наблюдаемым. Из теории управления следует, 
что наблюдаемость системы является важнейшим условием ее управляемости. Очевидно, что реализация давосских рекомендаций позволит поднять на качественно новый уровень технологии манипуляции общественного сознания и управления обществом, живущим в основном в виртуальном пространстве. По сути дела, жизнь большинства членов общества будет заменена ее компьютерной имитацией.

Серьезной угрозой общественной безопасности считается рост безработицы в связи с роботизацией рабочих мест, автоматизацией управленческих процессов, растущим применением 3D принтеров. Хотя эта проблема не нова и со времен первой промышленной революции ничего более болезненного для общества, чем движение луддитов, уничтожавших машины в Англии более двух столетий назад не было, сегодня она вызывает особое беспокойство. Действительно, в первое время массовой роботизации можно ожидать ощутимый рост безработицы среди рабочих и служащих определенных профессий и специальностей. Но, как показывает почти трехсотлетний опыт современного промышленного развития, эта угроза частично нейтрализуется другими факторами.

Во-первых, наряду с застойной безработицей в одних отраслях, всегда есть нехватка рабочей силы в других. Дисбаланс на рынке труда резко обостряется в период смены технологических укладов - в это время экономика погружается в депрессию в связи с прекращением расширения экономики в сложившихся направлениях, сокращением производства и инвестиций в отраслях, обеспечивавших в течение нескольких поколений трудоспособного населения основной рост занятости. Это вызывает шок и резкое падение доходов у многих ранее процветавших групп трудоспособного населения, значительная часть которых уже никогда не сможет восстановить свое положение. В то же время рост нового технологического уклада обеспечивает спрос на рабочую силу других специальностей и после переквалификации работники из устаревшего технологического уклада устраиваются по новой специальности. Государство может существенно смягчить диспропорции на рынке труда путем субсидирования программ переквалификации работников, своевременной перестройки системы образования под спрос на новые профессии.

Во-вторых, роботизация, как и цифровая революция в целом уже давно идет. Например, с 80-х годов прошлого века с ростом нового на тот момент 
информационно-коммуникационного технологического уклада автоматизация производства охватила множество отраслей обрабатывающей промышленности. Гибкие производственные линии сделали ненужными труд миллионов сборщиков, расфасовщиков, станочников. Жесткая автоматизация конвейерных производств высвободила еще миллионы людей, занятых монотонным трудом по выполнению простых рутинно повторяющихся операций. Прогресс в вычислительной технике ликвидировал миллионы рабочих мест машинисток, перфораторщиц, нормировщиков, проектировщиков, бухгалтеров и по другим специальностям, связанным с рутинными расчетами по установленным алгоритмам. Десятки миллионов замещаемых автоматикой людей оказались в трудном положении, но социального бедствия, подобного Великой депрессии, когда происходила предыдущая смена технологических укладов, не произошло. На самом деле промышленность по-прежнему является основой современной экономики, только на рынке труда ее доля резко снизилась до в среднем $25 \%$ в передовых странах.

В-третьих, для российского рынка труда последствия экономической политики еще долго будут намного более значимыми, чем цифровой революции. Вследствие резкой деградации экономики в связи с eе реформированием по рецептам МВФ были уничтожены целые отрасли промышленности с миллионами высокотехнологических рабочих мест. При этом наперекор общемировым тенденциям наиболее резкому сокращению подверглись производства современного технологического уклада, обеспечивающие расширение занятости во всем мире. Россия была и, отчасти, остается единственной страной в мире, где в 90 -е годы сокращалось число ученых, инженеров, программистов, операторов, наладчиков и других высококвалифицированных работников. Большинство из них вынуждены были перейти на низкоквалифицированную работу торговцев, перевозчиков, охранников. При переходе к политике опережающего развития экономики на основе нового технологического уклада российская экономика сталкивается с острой нехваткой специалистов инженерного профиля. Уже сейчас оживление экономики сдерживается нехваткой высококвалифицированных рабочих и инженеров.

В-четвертых, в обозримом будущем спрос на специалистов, необходимых для создания инфраструктуры цифровой экономики будет намного больше, 
чем связанное с ее расширением уничтожение рутинных рабочих мест. Это, правда, только в том случае, если цифровая экономика будет развиваться на отечественной интеллектуально-технологической базе. Если проводимая государством политика в сфере информационных технологий не изменится, и в ее основе будет лежать импорт техники и программного обеспечения, то эффект может оказаться и сильно отрицательным. Высвобождаемые, в основном уже из сферы услуг, главным образом финансового сектора и торговли, «белые воротнички» могут не найти себе новой специальности как из-за отсутствия должной квалификации, так и вследствие заполненности растущих сегментов российского рынка импортной техникой и иностранными специалистами.

Таким образом, угрозы резкого роста безработицы вследствие цифровой революции преувеличены. Они легко могут быть нейтрализованы продуманной государственной экономической политикой. До сих пор именно она, а не цифровая революция была главной причиной ликвидации миллионов рабочих мест и деградации человеческого капитала. Спрос на высококвалифицированных специалистов будет намного опережать их сокращение. Проблемой является наличие значительного числа малоквалифицированных и узкоспециализированных офисных работников, для трудоустройства которых потребуются значительные усилия по переквалификации. Но это тоже в решающей степени зависит от государственной политики.

Политической проблемой может стать использование цифровых технологий в сфере государственного контроля. К примеру, применение технологии блокчейн сделает невозможным фальсификацию регистрационных документов, подделку разрешительных документов, переделку «задним числом» проверочных актов. Эта технология также делает ненужной значительную часть дорогостоящих нотариальных услуг по заверению сделок. Применение «умных контрактов» затруднит чиновный произвол в сфере государственных закупок. Использование электронной цифровой подписи и методов точной идентификации бумажных и электронных носителей исключит подделку документов. Вся система государственного управления станет более прозрачной и открытой для общественного контроля. Сократится коррупционное поле и снизится потребность в чиновниках контролирующих органов. Может быть, поэтому информатизация систем государственного управления идет столь тяжело - 
гигантские деньги списываются на малоэффективные и дублирующие друг друга мероприятия.

Далее, говоря об обеспечении общественной и личной безопасности граждан, следует подчеркнуть фундаментальное значение решения задачи идентификации граждан в сети Интернет и социальных сетях. Без этого, как показывает опыт правоохранительной деятельности, совершаемые с использованием сети интернет преступления практически не раскрываются. Дела обстоят в этой области настолько скверно, что типичный случай мошенничества путем отказа от поставки проплаченного клиентом товара трудно даже зарегистрировать и возбудить уголовное дело по факту совершения преступления, не говоря уже о его расследовании. То же касается и более тяжких преступлений, совершаемых посредством социальных сетей, через которые происходит множество преступлений (особенно против несовершеннолетних, в том числе сексуального характера), включая сбыт наркотических и психотропных средств, вовлечение в экстремистские и преступные группировки, шантаж и доведение до самоубийства, вербовки иностранных спецслужб и пр.

Кроме решения задачи идентификации пользователей интернет и социальных сетей должны быть приняты дополнительные меры по обеспечению достоверности и легитимности распространяемой в них информации, в условиях всеобщей цифровизации, достоверность информации приобретает критическое значение. Целесообразно ввести ответственность социальных сетей за достоверную идентификацию их участников, а также за фильтрацию информации с целью выявления и пресечения противоправных действий со стороны злоумышленников.

Новой проблемой становится установление ответственности за правонарушения, совершаемые роботами в отношении людей. Уже активно ведется обсуждение вопроса об установлении виновных в случае дорожнотранспортных происшествий с участием беспилотного автомобиля. Аналогичные проблемы возникают в случаях нарушения условий поставок товаров в системах «умный дом» или хищения денег роботами. При столкновении беспилотников и в интернете вещей могут возникать похожие проблемы, но уже в отношениях между роботами.

По-видимому, нет другого пути, как введение уголовной ответственности юридических лиц за совершение преступлений принадлежащими им роботами и компьютерами. 
Сейчас рассматриваются три варианта отношений в социуме - цифровой тоталитаризм (пример, Китая), социал-демократия (Швеция) и цифровая экосистема (Америка). Ни один из вариантов не идеален. Часто каждый раз, когда нам кажется, что технология беспредельна, возникает препятствие: может быть, это этические ограничения, может быть, экономические, социальные или политические. Отметим, что опросы позволяют сделать вывод - у россиян нет спроса на тоталитарное государство.

Кризис настоящего периода, усугубленный шоком пандемии, нельзя определить как просто экономический кризис - именно цифровая индустрия стремительно росла и совершенствовалась. Сетевые взаимодействия позволили людям поддерживать друг и друга, особенно в ситуации отсутствия государственной поддержки. Отношения в социуме меняются. Если в 2017 году россияне ставили на первое место свободу, далее шла справедливость и замыкала триаду эффективность, то в 2020 году именно эффективность стала наиболее важной, а свобода оказалась на третьей позиции. Даже выбирая эффективность (здесь безопасность), жертвуя в той или иной мере свободой, 54\% граждан не согласны предоставлять какие-либо персональные данные государству без своего согласия. Из 40\% согласных при целевом условии: на борьбу с криминалом или на борьбу с пандемией. Защищенными свои данные считают $6 \%$. К слову, отметим, что еще в 30 -е годы XX века английский экономист Д. Кейнс показал, что невозможно одновременно максимизировать свободу, справедливость и эффективность.

Итак, цифровая экономика требует от человека и общества нового взгляда на жизнь. В постиндустриальном обществе взаимосвязи, коммуникации выстроены по сетевому типу. Для человека стало естественным жить не только в реальном, но и в виртуальном мире. В качестве участника коммуникаций в цифровой экономике место человека все чаще занимает его «виртуальный образ» - цифровой двойник. Технологии приводят к новым идеям и профессиям, меняют ценности и культуру. Человек, с одной стороны, является активным проводником технологических инноваций, с другой - максимально подвержен их влиянию. Одна из задач цифрового общества состоит в создании инструментов и методов вовлечения своих членов в активную деятельность по созданию новых продуктов, идей, технологий в противовес всепоглощающему обществу потребления [2]. 


\section{Список литературы}

1. Что такое цифровая экономика? Тренды, компетенции, измерение Ч-80 : Доклад к XX апр. Междунар. науч. конф. по проблемам развития экономики и общества, Москва, 9-12 апр. 2019 г. / Г.И. Абдрахманова, К.О. Вишневский, Л.М. Гохберг и др.; науч. ред. Л.М. Гохберг; Нац. исслед. ун-т «Высшая школа экономики». - М.: Изд. дом Высшей школы экономики, 2019. $-82 \mathrm{c}$.

2. Герасимчук 3.В. Социальные аспекты цифровой экономки / 3.В. Герасимчук, Н.Н. Голуб, Сторожук Р.П. // Научный вестник: Финансы, банки, инвестиции. - 2020. - № 1 - С.203 - 212.

(C) Н.А. Фаркова, 2021 